\title{
Environmental health risk by sly pollution: applied research on radon inside public buildings
}

\author{
S. Lo Nigro, F. Patania, A. Gagliano \& F. Nocera \\ Energy and Environment Division of D.I.I.M., \\ Engineering Faculty of University of Catania, Italy
}

\begin{abstract}
Radon ( $\mathrm{Rn})$ is a polluting gas coming from radioactive decays and it is not detectable by human senses as it is colourless, tasteless and odourless. Apart from the underground position of radioactive sources of such gas, it is able to cover very long paths through subsoil and to the surface at considerable distances from the underground starting points. Whenever it surfaces in the interior of buildings, passing through foundation structures, then it produces a sly pollution as its presence will be discovered only when it has harmed people. Owing to previous peculiarities, there is a considerable health risk in the case of such indoor air pollution and this risk can be mitigated only by precautionary measures as are used to periodically control Radon concentrations in indoor environments which are suspected to be polluted by Radon and then to set in action some techniques to reduce indoor radon concentration in polluted buildings. Beginning to face the Radon problem, the Province of Ragusa (Italy) set in action experimental research to discover the real concentrations of Radon in some public buildings in Ragusa town (ex IPAI building), Modica Town (technical Institute "Archimede") and Scicli Town (Civil Protection Agency Building). For reasons of space the aim of paper is to show results only for the IPAI building:

- The techniques and the equipment used to survey the gas concentrations.

- The analysis of results of the campaign of measurements that permit one to point out the reliability of methods as a function of the kinds of equipment.

- The proposed techniques of mitigation of pollution.
\end{abstract}

Keywords: radon, indoor pollution, measurements and control. 


\section{Site of research, techniques and equipment for measurements}

The whole of the research has been carried out in the towns shown by red spots in figure 1, that is the three towns of Sicily (Italy), but for reasons of space in this paper we will deal only with the part pertaining to the IPA building in Modica town where people attended a public school called "I.T.C. Archimede". In the campaign of measurement the following was carried out:

- Passive measures of $\mathrm{Rn}$ concentrations by method of gas absorption in active carcoil. The active carcoil was contained in canisters of metal, that is 70 gr. of carcoil for each canister with dimensions $\phi=10.2 \mathrm{~cm}$ and $\mathrm{h}=2.9 \mathrm{~cm}$ (figure 2 ). The measurements by canisters have been made with times of exposure of 48 hours for one week and repeated for four weeks. After exposure, carcoil has been analyzed in the laboratories of the Sicilian Centre of Nuclear Physic by sodium iodite spectrophotometer.

- Active measures of Rn concentration by Alphaguard - Genitron, that is a 3D ionisation chamber detector (figure 3) able to work both for "gaseous natural diffusion"(measurements of gas in the air) and "gaseous pumping diffusion" (measurements of gas in the subsoil)

Both kinds of measurements have been made in indoor rooms and in subsoil around the school. In the case of passive measurements in subsoil PVC tubes, appropriately punched, are positioned inside holes built in the ground (figures 4 and 5). The top of each tube has been closed with a special outlet plug able to house the canisters (figures 6 and 7) and all the holes in the top have been closed by a little inspection sump (figure 8 ). In the case of active measurement a probe has been positioned inside a PVC tube (figure 9) and connected to a 3D ionisation chamber by a very little tube in plastic material (figure 10). For outdoor measurement the equipment has been housed in a special metal container (figure 11).

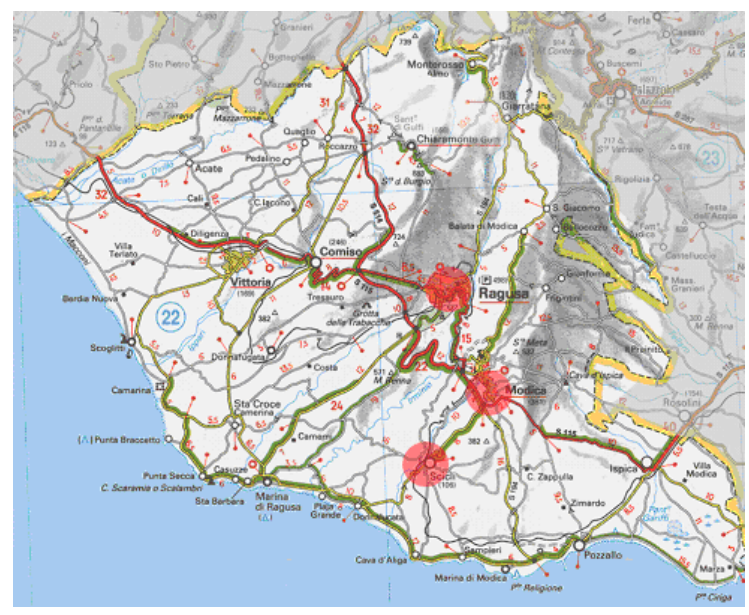

Figure 1: Site of research. 


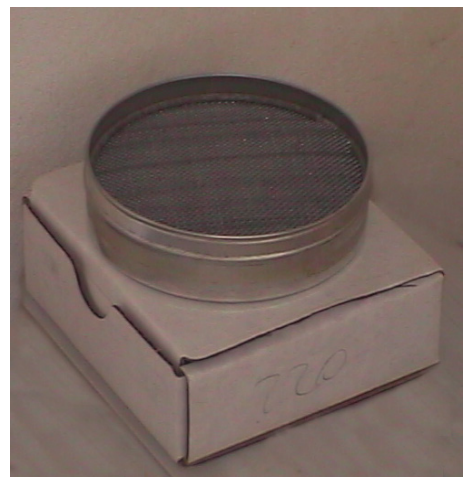

Figure 2: Carcoil container.

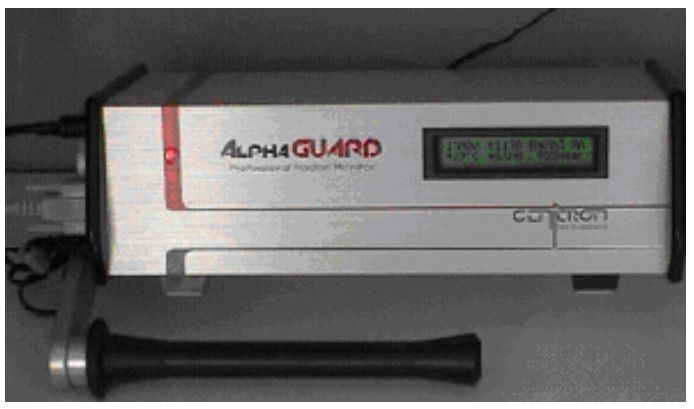

Figure 3: Ionisation chamber detector.

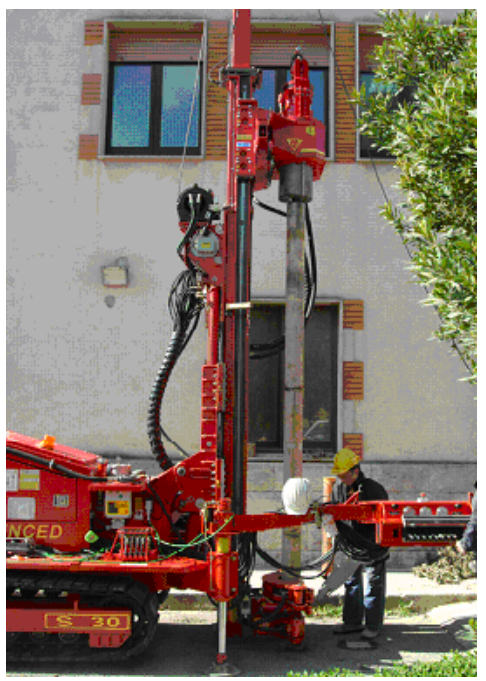

Figure 4: Hole preparation. 
182 Environmental Health Risk II

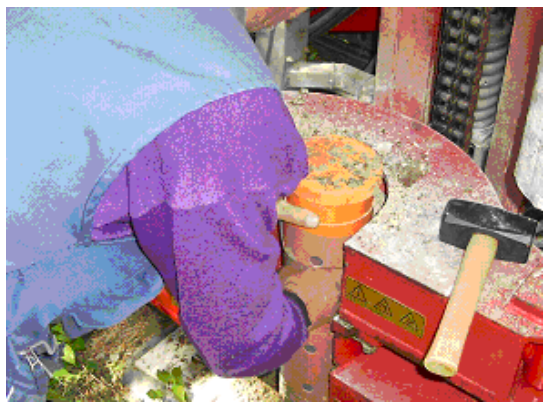

Figure 5: Tube positioning in the hole.

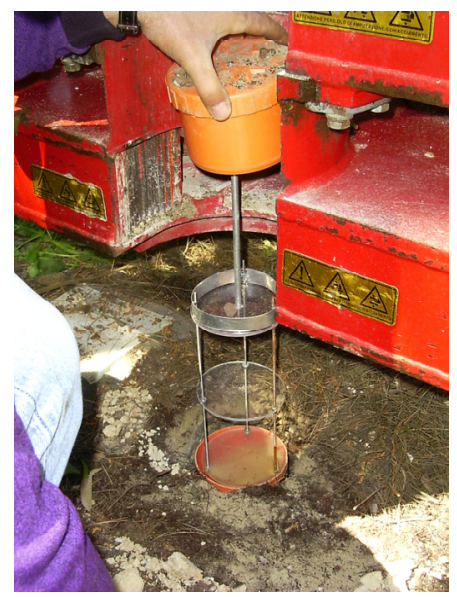

Figure 6: Outlet plug housing canister.

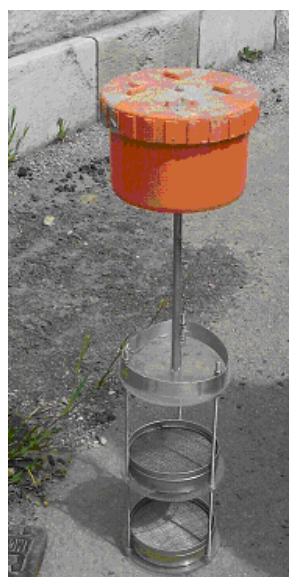

Figure 7: Plug with canisters. 


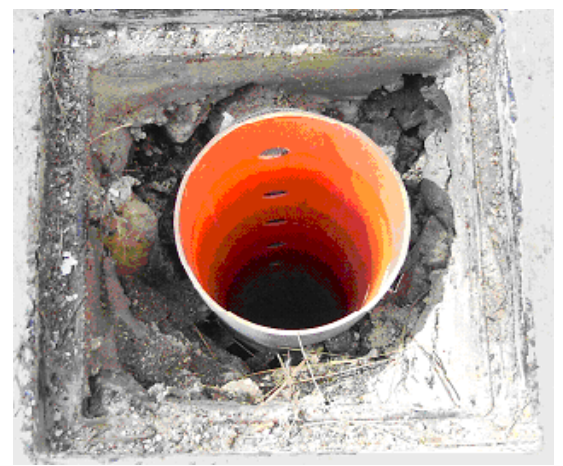

Figure 8: Inspection sump.

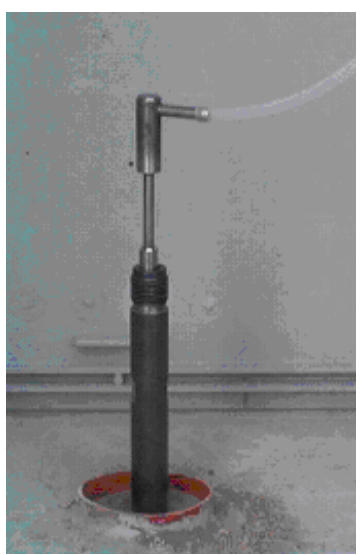

Figure 9: $\quad$ Probe.

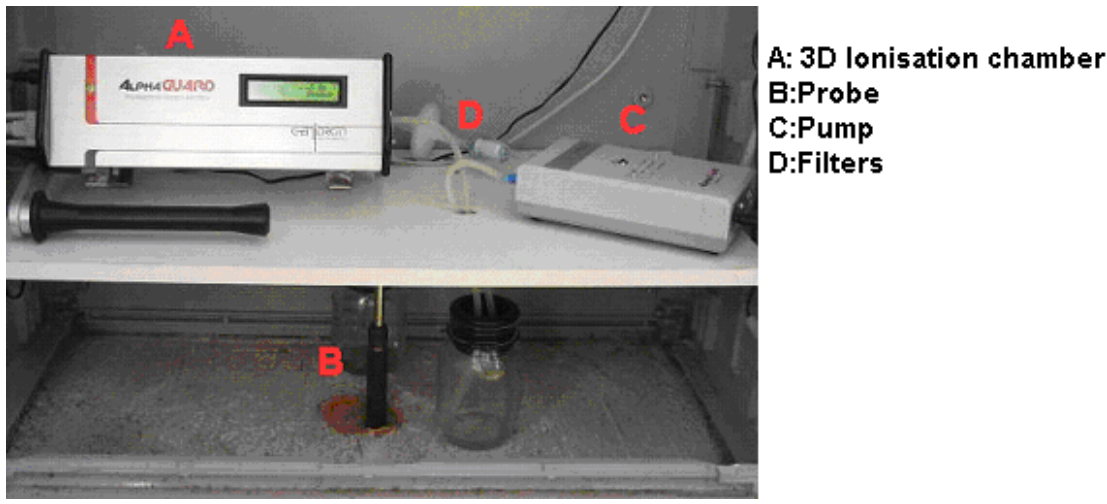

Figure 10: Equipment for active measures. 


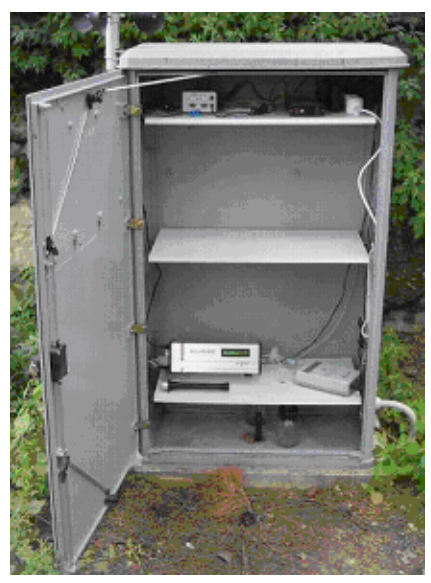

Figure 11: Container for equipment used in outdoor measurements.

\section{Factors favouring $R \mathbf{n}$ pollution indoors}

As is well known in technical literature [1-4], the factors are shortly summarised as follows:

- Intensity of gas flow coming from subsoil.

- Holes or breaks in trampling or in boundary walls that are in direct contact with the ground.

- $\quad$ Porosity and permeability of building surfaces in contact with the ground.

- Presence of doors and windows in the rooms.

- Presence of HVAC plants in the building.

- Ratio between the whole surface of the wrapper of the outside walls and that one in contact with the ground.

- Difference in air pressure between indoors and outdoors, independently from the producing causes.

- Presence of fine particulate matter $\left(\mathrm{PM}_{10}, \mathrm{PM}_{2,5}, \mathrm{PM}_{1,0}\right)$ in the air of indoor rooms.

- Climatic features in outdoor environments, especially referring to wind intensity and direction.

- Absence of air motions in the indoor environment.

\section{Results of campaign of measurements}

With reference to the maximum level of $\mathrm{Rn}$ concentration in the air, both Euratom 96/2000 directives and Italian law by decree n. 241/2000 fixed at 400 $\mathrm{Bq} / \mathrm{m}^{3}$ the alarm level for $\mathrm{RN}$ pollution. This value is estimated to be rather high by authors with particular reference to results carried out by ERRICCA European Project [5]. For reasons of space, some selected results are shown as follows: 
- Figure 12 shows an example of the measured values of Rn given off from the subsoil of building.

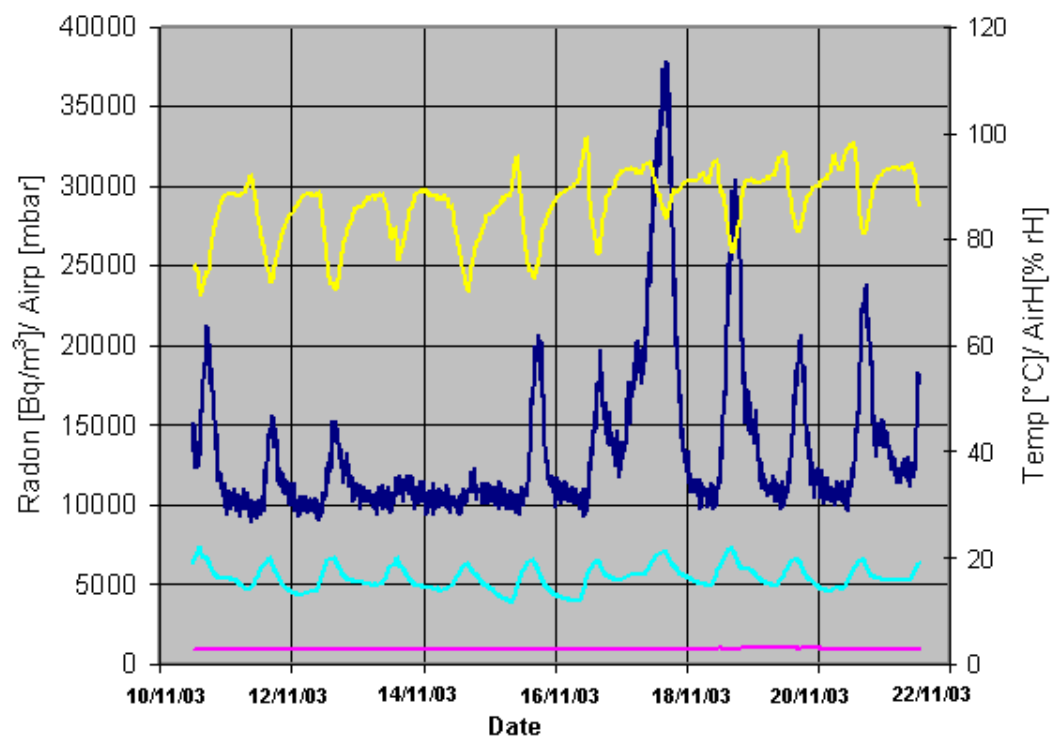

Radon $[\mathrm{Bq} / \mathrm{m} 3]$ - Air pressure $[\mathrm{mbar}]-$ Humidity $[\% \mathrm{rH}]$-Temperature ${ }^{\circ} \mathrm{C}$

Figure 12: $\quad$ RN given off from the subsoil of building.

- Figures 13 and 14 show examples of Rn measured values and indoor climatic features respectively for room $n .1$ and room n.4.

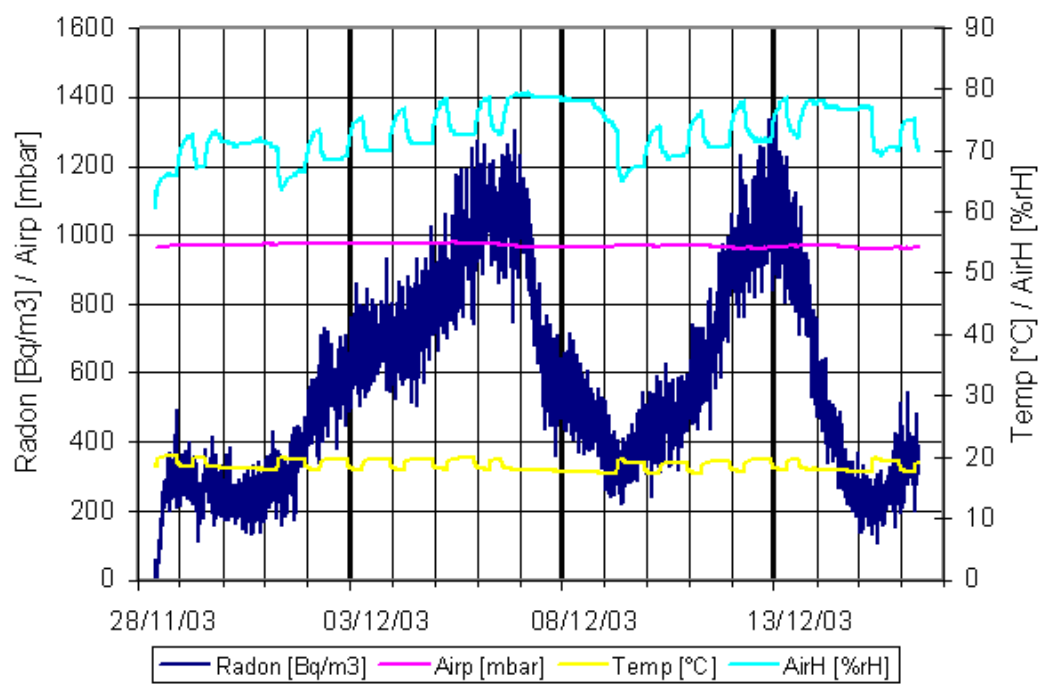

Figure 13: Indoor climatic features and RN concentrations in room n.1. 


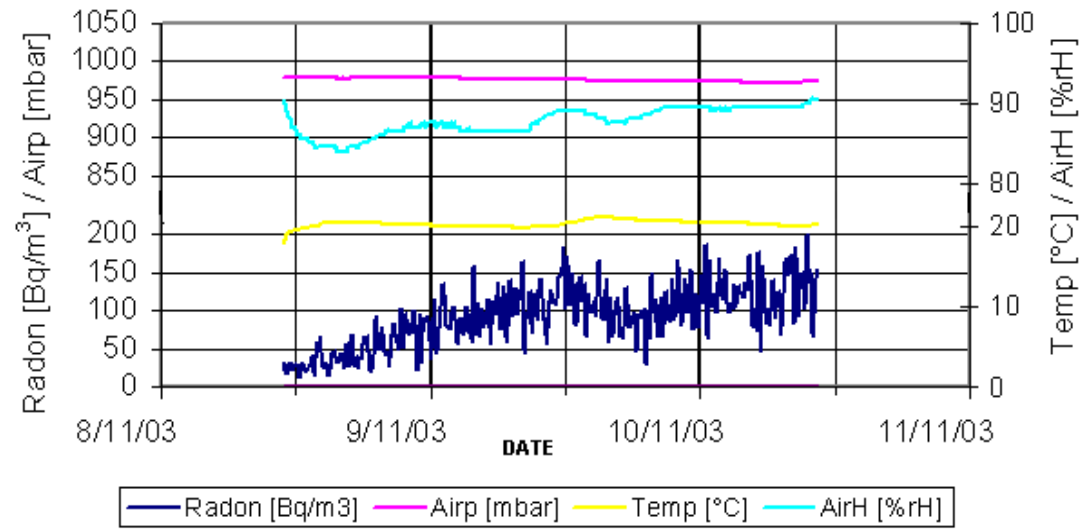

Figure 14: Indoor climatic features and RN concentrations in room n.4.

- $\quad$ Figure 15 shows the histogram of the average of $\mathrm{RN}$ concentrations for all rooms in the school.

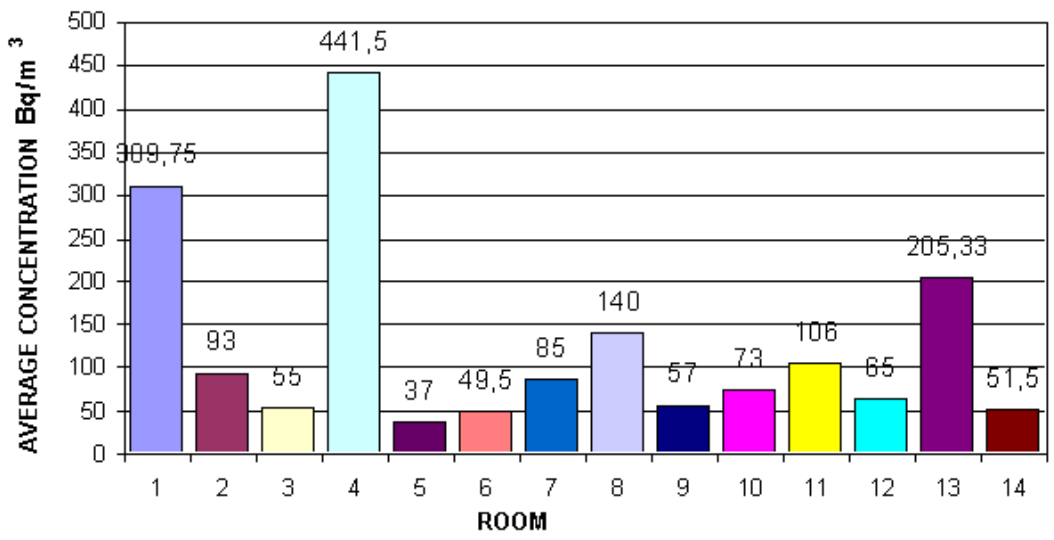

Figure 15: Average concentrations for each room of building.

- Table 1 shows an example of a comparison between data measured respectively by passive and active techniques.

Table 1: Data comparison between passive and active measurement techniques.

\begin{tabular}{|c|c|c|c|}
\hline Exposure Period & $\begin{array}{c}\text { Passive } \\
\text { Method } \\
\text { (canister) }\end{array}$ & $\begin{array}{c}\text { Active Method } \\
\text { (alphaguard mobile) }\end{array}$ & Factor \\
\hline $08-10$ November 2003 & $85 \mathrm{~Bq} / \mathrm{m}^{3}$ & $92 \mathrm{~Bq} / \mathrm{m}^{3}$ & 1.08 \\
\hline 9 November-01 December 2003 & $193 \mathrm{~Bq} / \mathrm{m}^{3}$ & $260 \mathrm{~Bq} / \mathrm{m}^{3}$ & 1.35 \\
\hline 13-15 December 2003 & $245 \mathrm{~Bq} / \mathrm{m}^{3}$ & $586 \mathrm{~Bq} / \mathrm{m}^{3}$ & 2.39 \\
\hline
\end{tabular}


For reasons of space it is not possible to show in this paper the peculiarities that caused the different values of $\mathrm{Rn}$ concentration in all of the investigated rooms, for this reason the authors prefer to draw the attention of readers to two particular cases, in fact a short analysis of the data in figure 15 to examine in detail rooms $n .1$ and $n .4$ that show a high average of $\mathrm{Rn}$ concentration and building peculiarities in accord with negative factors related in the previous paragraph n.2:

- Room n.1: mean average $309,75 \mathrm{~Bq} / \mathrm{m}^{3}$, maximum value $586,00 \mathrm{~Bq} / \mathrm{m}^{3}$. The room is utilised as the larder of the school, it has no windows and the inlet door is the only aperture of the room which looks towards the outdoor environment. In this room about $11 \mathrm{~m}^{2}$ of boundary surfaces are in direct contact with the soil, that is the floor made with marble slab upon a floor rough in concrete. Both the slab and the rough show evident cracks that permit the inlet of $\mathrm{Rn}$ from subsoil. The room is not frequently utilised and, in this way, there is no air motion or change of air: both factors favouring accumulation of Rn coming from subsoil into the room.

- Room n.4:mean average 441,50 Bq/ $/ \mathrm{m}^{3}$, maximum value $637,00 \mathrm{~Bq} / \mathrm{m}^{3}$. The room is utilised as a service room to the hydraulic plant of the building, in fact it houses the pumps and the other related hydraulic equipment. A lot of holes or breaks are in the trampling that separates the room by a water tank staying in underground under the room. This room, as the n.1 room, is not frequently utilised, has no windows and has no motions or changes of air.

With reference to the different techniques to measure $\mathrm{Rn}$ pollution, the results shown in Table 1 allowed the claim to be made that the direct measurements by Alphaguard are more reliable than the ones obtained by the canisters. In fact the values of measurements obtained by the canisters have been undervalued by up to $40 \%$ in some cases. One supposes that the undervaluation is caused both by the manipulation suffered by the canisters on the way from the experiment site to the analysis laboratory and by the time spent during the transportation the experiment site to the laboratory.
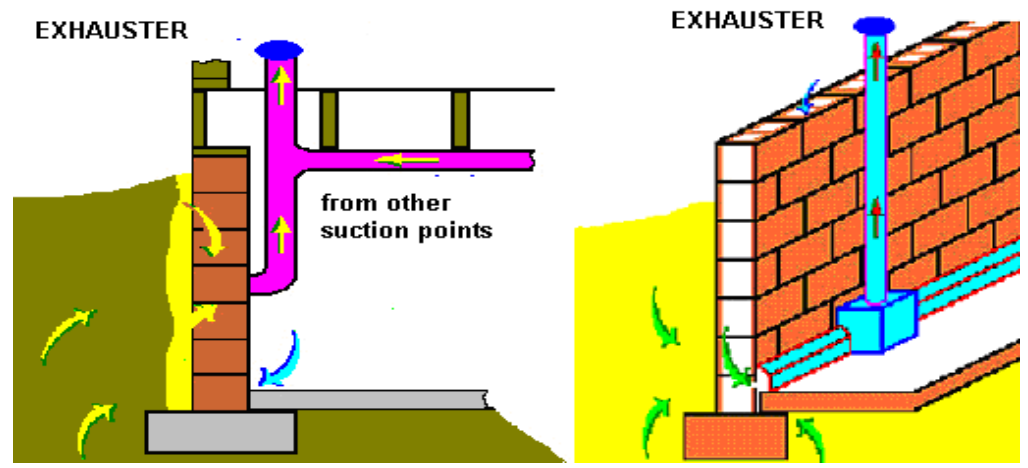

Figure 16: Block Wall Depressurisation and Base Board Depressurisation. 


\section{Conclusions}

The results of campaign of measurements and the investigations on situ permitted to focus on following remarks:

- $\quad$ the school is not very polluted by Rn gas, with a few exception: rooms nn. $1,4,8$ and 13

- $\quad$ to control and mitigate pollution in previous rooms the BBD (black Wall Depressurisation) or BWD (Based Board Depressurisation) (figure 16) techniques are suggested.

- $\quad$ Owing to very high emissions of $\mathrm{Rn}$ from subsoil (figure 12) people advise a continuous monitoring by active techniques in the class rooms

- The passive methods of measurement that do not offer a important reliability of measures could be used only for first general survey

\section{Acknowledgement}

The Authors wish to thank dott. Ing. Carlo Ricca for his precious contribution.

\section{References}

[1] ASTM Manual series: MNL 15- PCN 28-015094-17, "Radon, prevalence, measurements, health risk and control", Niren L. Nagda Editor, Philadelphia, June 1994.

[2] Patania F. and Gagliano A., Radon secret and detrimental effect on indoor health, II International Conference Cold Climate HVAC, Rowaniemy (Finland), March 1994.

[3] Patania F. and Gagliano A., Radon pollution dynamics in indoor environment: proposal about its control, International Conference Healthy Building, Budapest (Hungary), August 1994

[4] Patania F., Origini e controllo dell'inquinamento da radon parte I, Rivista Condizionamento dell'aria e refrigerazione n.11, pp. 1161-1168, Novembre 1995.

[5] Patania F. and Lo Nigro S., A new method to control health effect on radon indoor air pollution: final report", III International III International European Workshop (ERRICCA PROJECT FINAL REPORTED), Athens (Greece), March 1999. 